\section{Un nuevo papel para los pacientes en la investigación médica}

En un artículo reciente se destaca el valor potencial de emplear métodos de control del proceso estadístico para determinar los cambios en el estado de salud de pacientes con trastornos crónicos, que actúan como asociados de los investigadores. Se trata, básicamente, de aplicar los métodos estadísticos de control de la calidad junto con conceptos de mejora personal para medir los resultados de la atención de salud brindada a los pacientes. Se da como ejemplo el caso de dos pacientes diagnosticados de hipertensión en noviembre de 1996. Tras la prescripción de tratamiento, los pacientes recibieron esfigmomanómetros e instrucciones para su uso apropiado y para llevar un registro de lecturas diarias. En su seguimiento dos meses más tarde, se encontró que la tensión diastólica de un paciente había disminuido de 88 a 81 y la del otro paciente, de 93 a 86. Todas las medidas registradas en enero fueron menores que las de noviembre, probabilidad que representa un valor de $P=<0,01$. Aunque no pueden especificarse las razones de este cambio, es preciso considerar todo el complejo de actividades que entran en lo que llamamos "atención de salud", desde la instrucción educativa y mejor observancia del paciente hasta los resultados del medicamento y cierto efecto de placebo.

Ese mismo tipo de monitoreo puede llevarse a cabo fácilmente haciendo una representación gráfica en papel cuadriculado de las observaciones consecutivas registradas por el paciente. Para procesos estables observados por un tiempo, pueden calcularse los límites de control superior e inferior. En el caso de una persona con diabetes insulinodependiente, se registraron observaciones cuatro veces al día, en promedio, de los valores de glucosa en la sangre e insulina inyectada, así como el consumo de alimentos (gramos de grasa, carbohidratos y proteína), el ejercicio y la hora del día. Al cabo de un mes, esa persona comenzó a intervenir activamente para controlar su nivel de glucosa en sangre como preparación para participar en una carrera de larga distancia. Como resultado, la mediana de glucosa, originalmente de 130, disminuyó a 97 y la mediana del recorrido variable, que era de 68 , bajó a 24 . La paciente logró así no solo reducir la glucosa en sangre sino también reducir la variación. Los datos que ella registró se analizaron mediante el análisis de regresión de una serie cronológica. La nutrición, el ejercicio y la dosis de insulina al tiempo $t$ se usaron para predecir la concentración de glucosa al tiempo $t+1$. Se trazaron modelos separados para ambos tiempos. El primer tiempo incluía 51 mediciones consecutivas de glucosa y el segundo, 134. La diferencia entre la mediana de los valores fue significativa $(131 \pm 72$ frente a $98 \pm 30 ; P<0,01)$.

Hay métodos más complejos para analizar este tipo de datos. Uno que ha suscitado mucho interés entre estadísticos y practicantes del control de la calidad es el que enfoca el diseño del parámetro, ideado por Taguchi para reducir la variación en productos y procesos. El objetivo de este es lograr la función más robusta del sistema de ingeniería con el menor gasto posible controlando el "ruido" (las causas de variación). No es tan inverosímil como parece inicialmente aplicar este método a pacientes con enfermedades crónicas. El cuerpo humano es un sistema muy complejo, con factores controlables e incontrolables. En la diabetes insulinodependiente, pueden controlarse el tipo de insulina (de efecto inmediato o de efecto prolongado), el consumo de alimentos y el ejercicio. Con la cooperación del paciente, es posible experimentar hasta hallar la combinación de factores que mantengan a un nivel estable la glucosa en sangre. De ese modo, el proceso de mejora del paciente se centra en su persona. Dando un paso más adelante, pueden llevarse gráficos de control, no solo individuales, sino de grupos de pacientes similares. Frente a los ensayos clínicos aleatorizados, estos son registros rápidos y económicos con énfasis en los cambios. Además, la adición de pacientes bajo tratamiento similar permite monitorear los efectos de factores exógenos desconocidos que puedan afectar a los resultados.

Tanto los registros gráficos de control como los ensayos clínicos plantean dificultades de generalizabilidad, sesgo de información y anonimato. En el análisis multifactorial de los registros de control se usan series cronológicas mientras que en los ensayos puede usarse el análisis univariado o el de regresión. En los registros gráficos puede medirse la varianza, que por lo general se desconoce o se presume antes de los ensayos clínicos. Pero el poder estadístico de los diagramas reside en la representación de muchas medidas a lo largo del tiempo, enfoque que podría combinarse con los ensayos clínicos. Puede vislumbrarse un cuadro de pacientes hipertensivos que registran regularmente sus datos 
mientras participan en el ensayo clínico de un nuevo medicamento controlado con placebo y la asignación aleatorizada a un grupo de control y uno experimental. Se combinarían así los puntos fuertes de ambos sistemas a un costo relativamente bajo. El método de registros gráficos de control para la evaluación temprana de tratamientos antes de someterlos a costosos ensayos clínicos reduciría los gastos y aceleraría la disponibilidad de nuevos medicamentos en la práctica clínica. Puede también argumentarse que los registros son incluso preferibles a los ensayos en el sentido de que permiten una replicación rápida y frecuente (lo que constituye el patrón de oro), que no es posible con los ensayos clínicos. Por otra parte, dado que la mejor atención de los trastornos crónicos se basa en la medición frecuente de los síntomas, los pacientes tienen que actuar como asociados de los proveedores de la atención de salud. Acaso, en un futuro muy cercano, tendrán que hacerse aun más responsables de su propia salud. Por otra parte, en los ensayos se habla de $s u-$ jetos de estudio; psicológicamente, un asociado es un mejor recolector de datos que un sujeto de estudio. (Solodky C, Chen H, Jones PK, Katcher W, Neuhauser D. Patients as partners in clinical research: a proposal for applying quality improvement methods to patient care. Med Care 1998;36(8):AS13-AS20.)

\section{La crisis mundial de finanzas aumenta el riesgo de infecciones letales en los niños}

Los días 9 y 10 de noviembre de 1998 se celebró en Ginebra la conferencia internacional bienal del Grupo Consultivo de la Iniciativa en pro de la Vacuna Infantil (IVI). Esta es una coalición mundial de organizaciones públicas y privadas formada en 1990 con el fin de que todos los niños de todos los rincones del planeta reciban las vacunas que necesitan para protegerse contra las infecciones que hacen peligrar su vida. La IVI se reúne cada dos años para evaluar los progresos y buscar las formas de vencer los obstáculos que impiden su objetivo, y la actual crisis mundial de finanzas constituye un grave obstáculo. Los representantes de algunos países informaron que hay dificultades y retrasos para conseguir suficientes vacunas debido a las reducciones impuestas por sus gobiernos en los presupuestos destinados a la inmunización infantil. En algunos países se ha colapsado la moneda y el presupuesto no les permite comprar vacunas que tienen que pagar en divisas. En otros países que han podido comprar vacunas, se teme que pronto haya carencias que impidan inmunizar a todos los grupos susceptibles. La situación es especialmente precaria en los países que dependen de la ayuda extranjera o de divisas para comprar vacunas y administrar los programas de vacunación, en particular, países asiáticos y africanos. Sin embargo, también están en peligro algunos países grandes de América Latina. Sería una tragedia que los esfuerzos de los últimos 20 años de crear un sistema eficiente para la gran mayoría de los niños del mundo sufriera como resultado de una crisis financiera de corto plazo.

Por otra parte, aun sin la crisis hay muchos niños que no están recibiendo las vacunas que necesitan. Por lo menos $20 \%$ de los niños del mundo no están inmunizados con las vacunas básicas y los países más pobres todavía no pueden comprarlas. Esto podría explicar por qué, según las estimaciones del IVI, todavía mueren anualmente unos $4 \mathrm{mi}-$ llones de niños por infecciones que pueden prevenirse mediante vacunación. La mayor parte de esos niños pertenecen a los países más pobres, donde la entrega de vacunas no es suficientemente eficiente para lograr la cobertura necesaria, sobre todo en los lugares más remotos. De esos 4 millones de niños, 2 millones están muriendo porque no reciben vacunas elaboradas ya hace años, contra el sarampión, el tétanos, la rubéola y la fiebre amarilla. Otro millón de defunciones se debe a infecciones por virus de la hepatitis B y Haemophilus influenzae tipo B (causa común de influenza y meningitis). Muchos asistentes a la conferencia culparon la brecha entre ricos y pobres por estas muertes innecesarias. Esa brecha se está agrandando cada vez más y la crisis agrava la situación. Cualquier niño que nace en un país en desarrollo tiene un riesgo 1000 veces mayor de contraer sarampión y morir por esa causa que un niño nacido en un país industrializado.

La vacunación de los niños no es solo cuestión del presupuesto nacional. También es afectada por problemas sociales, como indica el brote reciente de poliomielitis an Albania (el primero en 18 años) y el de difteria en los países que constituían la antigua Unión Soviética. La vida de los 4 millones de niños que mueren todos los años por falta de vacunación podría salvarse si se cumplen dos condiciones, concluyeron los asistentes a la conferencia de la IVI. En primer lugar, los gobiernos tienen que dar la absoluta primera prioridad a las vacunas y la vacunación y no gastar en cosas menos costo-eficaces, como los hospitales de alta tecnología. Segundo, el mundo tiene que doblar la cantidad anual que gasta (US\$ 10000 millones) en todos los aspectos de vacunación, desde la investigación hasta el desarrollo y la distribución. Hoy día esa cantidad corresponde a US\$ 1,80 por persona, mientras que se gastan US\$ 139 por persona en equipo militar.

Del lado positivo, se señaló que las vacunas pediátricas tradicionales (contra tuberculosis, poliomielitis, difteria, sarampión, tétanos y pertussis) llegan a $80 \%$ de los niños del mundo, frente a $5 \%$ hace solo 20 años. Los servicios ordinarios de vacu- 
nación de todo el mundo están salvando anualmente las vidas de 3 millones de niños y previniendo la ceguera, la parálisis y la discapacidad mental de otros 750000 a un costo de menos de US\$ 15 por niño en los países más pobres. Las nuevas vacunas recién desarrolladas -contra neumonía, meningitis y rotavirus- podrían salvar a otros 2 millones. La investigación sobre vacunas nunca ha sido tan activa ni tan promisoria, con 250 nuevas vacunas en distintas etapas de investigación y desarrollo. Mientras tanto, las comunidades están intentando simplificar los programas de vacunación para lograr una cobertura mayor. La poliomielitis actualmente está limitada al sur de Asia y el África subsahariana. Por último, alrededor de 100 países usan regularmente la vacuna contra la hepatitis B, frente a 20 países en 1990. En muchos de esos países, la vacunación ha reducido la proporción de portadores del virus de $10-15 \%$ a menos de $2 \%$. En algunos casos, las tasas de cáncer de hígado en los niños se han reducido a la mitad desde que se implantó el uso de esa vacuna. (Organización Mundial de la Salud. Global financial crisis increases risk of deadly child infections, Children's Vaccine Initiative says. Comunicado de prensa WHO/83, 10 de noviembre de 1998.)

\section{¿Se requiere un tratamiento específico para las mujeres con VIH?}

Se acaban de publicar los resultados de un estudio de drogadictos infectados por el virus de la inmunodeficiencia humana (VIH) patrocinado por el Instituto del Abuso de Drogas de los Institutos Nacionales de Salud de los Estados Unidos de América. El estudio de 650 sujetos, llevado a cabo por un equipo de investigadores de la Universidad Johns Hopkins, indica la posibilidad de que las mujeres con VIH-1 que han sido usuarias de drogas intravenosas requieran un régimen diferente de tratamiento antisida que el que se les ofrece actualmente. Según el estudio, entre las personas que progresaron al sida, las concentraciones de VIH eran notablemente más bajas en las mujeres que en los hombres. Esto sugiere que las mujeres drogadictas con infección por VIH progresan más rápidamente al sida que los hombres con la misma carga vírica. Por ejemplo, de acuerdo con tres diferentes métodos de cálculo, las mujeres del estudio tenían cargas víricas correspondientes a entre 38 y 65\% de las de los hombres. En las personas que participaron en el estudio, ambos sexos progresaron al sida con igual rapidez una vez infectados, lo cual muestra que las mujeres usuarias de drogas por inyección desarrollan el síndrome con la mitad de la carga vírica que tienen los hombres. Además, con cargas víricas iguales a las de los hombres, las mujeres tenían un riesgo 1,6 veces mayor que los hombres de progresar al sida.

Estos resultados podrían representar el primer paso hacia una nueva comprensión del desarrollo del VIH al sida en cada sexo. Ahora será necesario seguir investigando a ver si los resultados son similares en grupos que no han usado drogas. De todos modos, si la carga vírica en las mujeres estudiadas tiene una significado clínico diferente al que tiene en los hombres, es necesario tenerlo en cuenta para encauzar su tratamiento de forma distinta. La carga vírica se midió en una primera visita y en visitas posteriores 3 años después. El estudio se diseñó con objeto de analizar la relación entre la enfermedad y el sexo de la persona enferma midiendo la carga vírica individual con tres métodos distintos. Los resultados sorprendieron a los investigadores, que esperaban que una menor carga vírica se asociara con una progresión más lenta al sida. Las razones de los resultados obtenidos aún no se han dilucidado y los investigadores están considerando las siguientes hipótesis: una dinámica diferente del VIH-1 en cada sexo, diferencias conductuales que pudieran afectar a la carga vírica y diferencias hormonales. (Farzadegan $\mathrm{H}$, Hoover DR, Astemborski J, Lyles CM, Margolick JB, Markham RB, et al. Sex differences in HIV-1 viral load and progression to AIDS. Lancet 1998;352: 1510-1514.)

\section{La aterosclerosis puede ser causada por bacterias}

Según ha descubierto un grupo de cirujanos de la Universidad de Colorado, hay una relación causal entre Chlamydia pneumoniae, una bacteria común que produce síntomas respiratorios y la aterosclerosis (endurecimiento de las arterias). En un informe presentado ante el Congreso Clínico de 1998 del American College of Surgeons, los investigadores declararon que C. pneumoniae había hecho crecer in vitro células de músculo liso de aorta humana. Las bacterias también estimularon en dichas células la liberación de citoquinas, sustancias químicas que inducen a un mayor crecimiento.

En la investigación, se añadieron bacterias de C. pneumoniae a platos Petri que contenían células de músculo liso de aorta humana porque estas células sirven de fundamento para la formación de las lesiones ateroscleróticas avanzadas. Las bacterias triplicaron el número de células y doblaron el ritmo de su proliferación según la actividad mitocondrial, además de aumentar dos veces y media la concentración de las citoquinas proinflamatorias 6 y 8. Las células de músculo liso ocupan la mayor parte de la pared de los vasos sanguíneos. Su proliferación y 
el aumento de citoquinas muestran una actividad de las clamidias que es preciso descifrar con mayor detalle.

Estos resultados se han comparado con el descubrimiento de que la úlcera péptica es causada por Helicobacter pylori, lo que hace unos años cambió inmediata y radicalmente el tratamiento de esa enfermedad. Hoy día no se operan las úlceras, sino las complicaciones de la enfermedad, ya que el tratamiento con antibióticos cura a la gran mayoría de los pacientes. En el caso de C. pneumoniae, la posibilidad de mayor interés es que pueda administrarse un tratamiento contra la bacteria que al eliminar el microorganismo tenga un impacto notable en el desarrollo de la enfermedad cardiovascular.

Si bien es demasiado pronto para derivar de esta información inferencias útiles con respecto al tratamiento de pacientes con aterosclerosis, el doctor C. Selzman, uno de los autores del estudio, indicó que la terapia antibiótica contra C. pneumoniae no daría resultados espectaculares. La aterosclerosis tiene demasiadas variables para que la erradicación del factor que incita el proceso inflamatorio revierta la enfermedad. No obstante, es posible que la terapia antibacteriana atenúe el progreso de la aterosclerosis. Un ejemplo de ese tipo de mejora ocurre cuando se trata a pacientes que tienen altas concentraciones de colesterol sérico con agentes que disminuyen esa sustancia, lo que redunda en una reducción de la incidencia de accidentes cardiovasculares.

Es probable que hasta $50 \%$ de las personas en los Estados Unidos tengan anticuerpos contra C. pneumoniae como resultado de alguna infección en el pasado. Este microorganismo causa un tipo corriente de "neumonía ambulatoria" que a menudo cursa sin prostración y permite al paciente continuar con sus actividades cotidianas. En los grupos de más de 50 años, más de la mitad tienen los anticuerpos. Si los estudios ulteriores confirman que C. pneumoniae es una causa de aterosclerosis, el tratamiento para algunos pacientes en riesgo podría cambiar. Se intentaría examinar a los pacientes con factores de riesgo de enfermedad cardiovascular, por ejemplo, con altas concentraciones séricas de colesterol o hipertensión, para determinar si tienen anticuerpos a la bacteria. Los pacientes con títulos altos recibirían antibióticos para erradicar el microorganismo y reducir así el riesgo de enfermedad cardiovascular. (Selzman $\mathrm{CH}$, Weinberg A, Miller SA, Netea MG, Young P, Harken AH, et al. Strain of bacteria may be a cause of atherosclerosis. News from the American College of Surgeons (paquete de informes presentados al Congreso Clínico del American College of Surgeons, 25 a 30 de octubre de 1998, Orlando, Florida.)

\section{La supresión del VIH requiere tratamientos intensivos}

Desde principios de 1997 se ha estado llevando a cabo un estudio clínico de gran envergadura para determinar si, una vez moderada la producción de VIH por medio de terapia intensiva, se requiere uno o más medicamentos para mantener la disminución del virus. Este estudio multicéntrico incluye a más de 500 pacientes, cada uno de quienes tenía cargas víricas de más de 1000 copias de ARN por ml de sangre y por lo menos 200 células T CD4+ por $\mathrm{mm}^{3}$ al comenzar el estudio. Durante la fase inicial de la investigación, todos recibieron el medicamento indinavir (IDV) (inhibidor de la proteinasa) combinado con zidovudina (AZT) y lamivudina (3TC). Después de 6 meses, más de 300 de los pacientes cuyas cargas de VIH se habían reducido a 200 o menos copias de ARN $/ \mathrm{ml}$ se distribuyeron aleatoriamente en tres grupos que recibieron, respectivamente, la misma terapia inicial con tres medicamentos, una combinación de AZT y 3TC y monoterapia con IDV. Los investigadores de la Unidad de Ensayos Clínicos sobre el Sida - ubicada en San Diegode la Universidad de California, midieron las cargas víricas de los sujetos a intervalos regulares para determinar si había ocurrido rebote de la carga vírica, definido como dos mediciones consecutivas de más de 200 copias de ARN/ml. Se encontró que había ocurrido rebote en 51 participantes: 4 en el grupo de terapia triple, 24 en el de dos medicamentos y 23 en el de monoterapia. Hubo una diferencia estadísticamente significativa entre el primer grupo y los otros dos. Sin embargo, entre los pacientes que no habían tomado AZT antes de iniciarse el estudio, la diferencia entre la terapia triple y la doble no fue estadísticamente significativa.

Una carga vírica grande al entrar al estudio y tasas de aclaramiento vírico lento fueron factores de riesgo de rebote. La presencia de mutaciones resistentes a la AZT fue fuertemente predictiva de rebote en el grupo con dos medicamentos. Un efecto interesante fue la fuerte correlación entre la magnitud del aumento de células T CD4+ y el rebote. El riesgo de rebote aumentó $30 \%$ por cada aumento de 100 en el recuento de dichas células. Esto se explica porque un aumento en las células T CD4+ aumenta el número de células objetivo disponibles para una nueva infección por $\mathrm{VIH}$, lo que puede ocurrir cuando se instituyen terapias menos intensivas.

Los investigadores han llegado a la conclusión de que mantener la supresión de VIH con terapia antirretrovírica deja poco margen para error. La falta de observancia de cualquier componente del régimen puede causar rebote de la carga vírica. Para mantener la supresión de los virus, la terapia con tres medicamentos parece ser superior a las menos 
intensivas o "de mantenimiento". Entre los participantes, los que cambiaron de las terapias con dos o tres medicamentos a la monoterapia fueron más susceptibles de experimentar el resurgimiento de las concentraciones de VIH. Parece claro que los pacientes que responden bien a la terapia antirretrovírica intensiva deben continuar con ese tipo de tratamiento. Lo mismo puede aducirse de otras investigaciones en las que se describen reservorios persistentes en personas que están recibiendo terapia antirretrovírica muy activa aun después de que la carga vírica ha llegado a ser indetectable.

Los resultados del ensayo son un poco decepcionantes, pero se continuará estudiando el problema e intentando simplificar el tratamiento de la infección por VIH. Con objeto de mantener la supresión vírica, es posible que la terapia inicial, la de mantenimiento o ambas tengan una potencia virológica mayor que los regímenes empleados en esta serie de ensayos. También es posible que los períodos largos de inducción o simplemente regímenes diferentes sean más efectivos. (Institutos Nacionales de Salud, Instituto Nacional de Alergias y Enfermedades Infecciosas (EUA). Study finds less intensive treatments may not maintain HIV suppression. NIH News Release, 28 de octubre de 1998.)

\section{La nicotina actúa en el cerebro como las drogas adictivas}

Todas las sustancias adictivas perturban el flujo normal de la neurotransmisora dopamina en el sistema nervioso central mediante su liberación en el cerebro. Se cree que esa actividad contribuye de forma significativa a la sensaciones de placer y recompensa asociadas con las drogas y, con el tiempo, a la adicción y la vulnerabilidad que causa su abstinencia. Las drogas adictivas comienzan su acción ligándose por enlaces químicos a receptores moleculares, algunos de los cuales se encuentran en las células nerviosas de la dopamina. A raíz de varias investigaciones recientes patrocinadas por el Instituto Nacional del Abuso de Drogas, se ha comprobado que la nicotina no solo es adictiva, sino que afecta al mismo mecanismo que las drogas adictivas y aumenta la concentración encefálica de dopamina. Estos hallazgos también apuntan hacia la forma en que la abstinencia de nicotina activa los sistemas de estrés del organismo. Dos equipos de investigadores han descrito cómo la nicotina, al igual que la heroína y la cocaína, activa células nerviosas que contienen dopamina en el sistema mesolímbico, que se relaciona con las emociones y el comportamiento. Otro grupo ha descubierto que la abstinencia de nicotina después de su uso crónico, produce cambios similares a los que ocurren al abstenerse de otras drogas adictivas.

La nicotina se enlaza con múltiples receptores en las células nerviosas de la dopamina o las neuronas, para activar las neuronas. Teóricamente, así empieza la respuesta que conduce a las sensaciones de placer y recompensa y por último, a la adicción. Al examinar en murinos células nerviosas de dopamina expuestas por períodos prolongados a la nicotina, se encontró que a concentraciones comparables a las que reciben los humanos que fuman, la nicotina primero activa o sensibiliza esas neuronas y luego las desensibiliza. Quizá esa desensibilización explica por qué los fumadores se vuelven tolerantes a los efectos de fumar durante el día, tolerancia que desaparece durante la noche. Podría ser la razón de que los fumadores consideren el primer cigarrillo del día el más agradable, pero a medida que pasa el día el placer se reduce. En último término, estos efectos afectan al comportamiento de las personas que fuman.

Uno de los grupos de investigadores que estudian los mecanismos del tabaquismo ha encontrado la proteína exacta a la cual se enlaza la nicotina en las células de dopamina. Una línea de murinos que carecen del gen que codifica esa proteína (denominada subunidad beta 2) resultaron indiferentes a la nicotina en contraste con los que tienen el gen. Sin embargo, estos mismos roedoes se vuelven adictos a otras sustancias como la cocaína. Tampoco se consiguió aumentar la concentración de dopamina en el cerebro de los murinos inyectándolos directamente con nicotina. Es evidente que si se elimina la subunidad del receptor nicotínico, desaparece la capacidad para estimular la liberación de dopamina. Se abre así la posibilidad de inventar medicamentos contra la adicción de nicotina dirigiéndolos a esa proteína.

También se está estudiando cómo el receptor de la nicotina y sus subunidades afectan la sensibilidad a otras drogas como la morfina, la cocaína y el alcohol. Las personas que abusan de las drogas suelen fumar, por lo que interesa conocer las interacciones entre los sistemas que median los efectos placenteros e esas sustancias. (Swan N. Like other drugs of abuse, nicotine disrupts the brain's pleasure circuit. NIDA Notes 1998; 13(3):8, 9, 12.) 